\title{
Editorial
}

\section{Tosferina: Infección reemergente}

La tosferina es una enfermedad infecciosa que tradicionalmente se ha considerado típica de la niñez e incluso erradicada; sin embargo desde la década de los 80 se ha identificado a nivel mundial un cambio epidemiológico caracterizado por un aumento en el reporte de casos y con brotes cada 3-4 años, afectando adolescentes y adultos que se convirtieron en la principal fuente de contagio de lactantes menores. Aún así, el número de casos reportados continúan siendo mucho menores que las cifras vistas en la época pre vacunal. Estados Unidos, Canadá, Australia y algunos países europeos han reportado un incremento en el número de casos, Estados Unidos reporta para el año 2004, 26000 casos, cifra sólo superada en la epidemia de 1950. Tanto en Estados Unidos como en Canadá, los adolescentes representan el grupo de ataque más importante. Se ha calculado que 7\% de todos los episodios tusígenos de los adultos corresponden a tosferina.

En Costa Rica la situación no ha sido diferente (Figura 1), en el año 2001 en el Hospital de Niños se reportó un aumento de los pacientes que requerían internarse con el diagnóstico de síndrome tosferinoso, el diagnóstico era eminentemente clínico y sólo se contaba con una prueba de inmunofluorescencia indirecta que identificaba Bordetella sp. A partir de entonces se ha mejorado la capacidad diagnóstica del laboratorio de referencia (INCIENSA) y sobre todo la sospecha diagnóstica entre los clínicos. En la actualidad se cuenta con cultivo bacteriano y reacción en cadena de polimerasa, lo que permite tener un panorama epidemiológico más completo.

\section{Definición de Caso Clínico}

Tomando en consideración que la presentación clínica ha variado y que la anterior definición de tos cianotizante, hemetizante y en paroxismos ya no aplicaba, la nueva definición incluye otros criterios: Tos de cualquier tiempo de evolución, por lo general de 2 o más semanas, con al menos uno de los siguiente: paroxismos, ruido inspiratorio, vómitos post-tusígenos, apnea, sin otra causa aparente.

Por lo general los adolescentes y adultos sufren un cuadro leve de tos de 2 a 4 semanas de evolución, usualmente nocturna, que se exacerba con la comida y la bebida; sin compromiso del estado general. Sin embargo en los lactantes de 6 meses de edad o menos la tosferina tiende a complicarse y es en este grupo de edad que se observan las tasas más altas de hospitalización, neumonía, convulsiones, encefalopatía, hipertensión pulmonar y muertes. La apnea es uno de los signos más comunes en los menores de 6 meses.

El aumento en el número de casos en lactantes menores (Figura 2) y sobre todas las muertes que para este año contabilizaron 6 (Figura 3), amerito que se planeará una estrategia para reducir el riesgo de enfermar y de morir a causa de esta infección. La estrategia definida fue la denominada "estrategia capullo" que consiste en lograr la protección del recién nacido a través de la vacunación en la madre. Basándonos en datos internacionales, confirmados en nuestro medio, que evidenciaban que la mayor parte de las veces la madre es la fuente de contagio de los recién nacidos a partir del 30 de abril de este año, se inicia la vacunación en las madres en el post-parto inmediato, como población meta y a todos los padres que solicitaran la inmunización, utilizando la vacuna dTap. La misma tiene por objeto reducir el número de madres que desarrollan cuadros asintomáticos o sintomáticos de tosferina y lograr a través del paso de anticuerpos por leche materna la protección adicional del recién nacido; el aumento de anticuerpos en la madre empieza en el día 7 post-vacuna y la edad promedio de la infección en el recién nacido, según datos

ISSN 0001-6002/2007/49/3/134-135 Acta Médica Costarricense, (C2007 Colegio de Médicos y Cirujanos nacionales, ha sido de 45 días. 


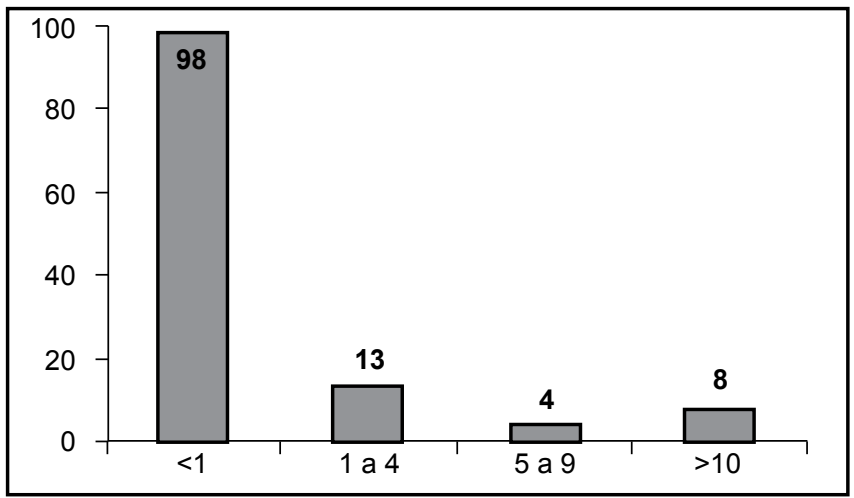

Figura 1. Distribución Etaria (\%) Casos de Tosferina 1993-2006 Fuente: Vigilancia de la Salud, Ministerio de Salud, Costa Rica.

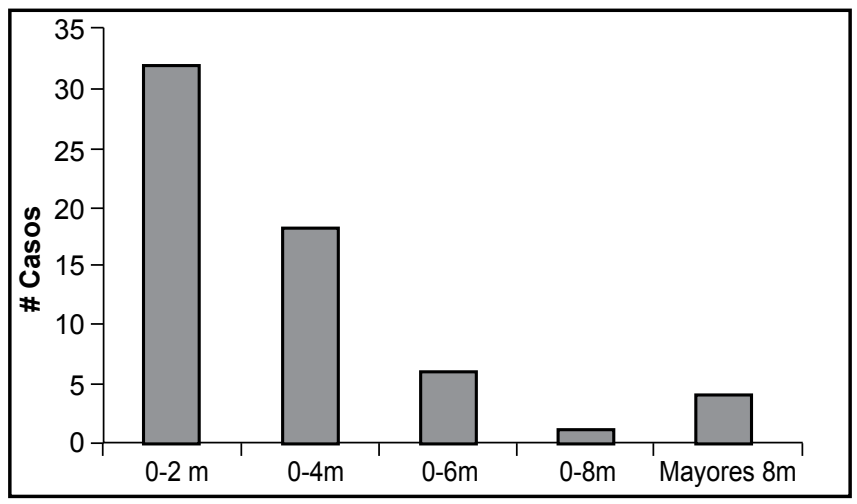

Figura 2. Distribución por Grupos de Edades. Hospital Nacional de Niños de Costa Rica 2007. Fuente: Ulloa-Gutiérrez 2007.

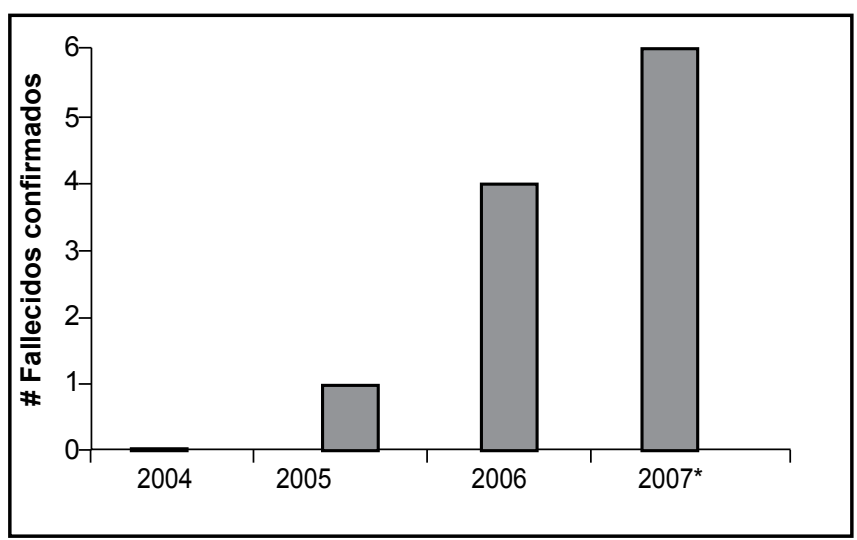

Figura 3. Fallecimientos Confirmados Tosferina. Hospital Nacional de Niños de Costa Rica 1 Enero 2004 - 31 mayo 2007 *. Fuente: Ulloa-Gutiérrez 2007
Luego de 45 días de haber iniciado la vacunación en las 24 maternidades. Se han distribuido 29.000 dosis, de las cuales se han aplicado 17576 dosis. Con esas dosis se han protegido 8753 recién nacidos. No se han dado casos de rechazo a la vacuna, ni se han reportado reacciones adversas a la misma.

Los pasos siguientes serán medir el impacto de la estrategia en la reducción de casos, avanzar en el plan nacional de vacunación con la introducción de la vacuna acelular contra tosferina en los adolescentes después de los 14 años y reforzar la vigilancia epidemiológica de esta y otras eventuales.

La tosferina esta presente en nuestro medio, debemos mantener un alto índice de sospecha clínica y considerarla entre el diagnóstico diferencial de todo episodio tusígeno de más de dos semanas de evolución en cualquier grupo etario, especial cuidado se debe tener con los niños menores de 6 meses por las altas posibilidades de complicación y de eventual muerte.

Agradecimiento: Especial reconocimiento para los miembros de la Comisión Nacional de Inmunizaciones y Vigilancia Epidemiológica por el arduo trabajo realizado en torno a este tema, en especial al Dr. Daniel Salas, la Msc Vicenta Machado y al Dr. Rolando Ulloa-Gutiérrez

María Luisa Ávila-Agüero

Ministra de Salud

\section{Referencias}

1. Greenberg DP. Pertussis in adolescents: increasing incidence brings attention to the need for booster immunization of adolescents. Pediatr Infect Dis J. 2005; 24:721-8.

2. Skowronski DM, De Serres G, MacDonald D, et al. The changing age and seasonal profile of pertussis in Canada. J Infect Dis. 2002;185:1448-53

3. Cherry JD. Immunity to pertussis Clin Infect Dis. 2007; 15;44:1278-9.

4. Kowalzik F, Barbosa AP, Fernandes VR, Carvalho PR, Avila-Aguero ML, Goh DY, Goh A, et al. Prospective multinational study of pertussis infection in hospitalized infants and their household contacts. Pediatr Infect Dis J. 2007;26:238-42

5. Mooi FR, de Greeff SC. The case for maternal vaccination against pertussis. Lancet Infect Dis. 2007; 28

6. Forsyth KD, Wirsing von Konig CH, Tan T, Caro J, Plotkin S. Prevention of pertussis: recommendations derived from the second Global Pertussis Initiative roundtable meeting. Vaccine. 2007;25:2634-42.

7. Forsyth KD, Campins-Marti M, Caro J, Cherry JD, Greenberg D, Guiso N, et al. New pertussis vaccination strategies beyond infancy: recommendations by the global pertussis initiative. Clin Infect Dis. 2004;39:1802-9

8. Forsyth $\mathrm{K}$, Tan $\mathrm{T}$, von König $\mathrm{CH}$, Caro JJ, Plotkin S. Potential strategies to reduce the burden of pertussis. Pediatr Infect Dis J. 2005;24:S69-74. 